\title{
Cervical ependymoma: Case report and review of the literature
}

\author{
Ersoy Kocabıçak*a, Cengiz Çokluk ${ }^{\text {a }}$, Keramettin Aydına, Yaşar Bayria ${ }^{\mathrm{a}}$, Yurdanur Süllü̈ \\ ${ }^{a}$ Department of Neurosurgery, Medical Faculty, Ondokuz Mayis University, Samsun, Turkey \\ ${ }^{b}$ Department of Pathology, Medical Faculty, Ondokuz Mayis University, Samsun, Turkey
}

\begin{tabular}{|c|c|}
\hline ARTICLE INFO & ABSTRACT \\
\hline Article History & \multirow{13}{*}{$\begin{array}{l}\text { Intramedullary ependymomas are rare tumours but comprise the majority of intrame- } \\
\text { dullary glial neoplasms in the adult. In this case report we introduced a } 51 \text { year old male } \\
\text { patient with one month history of pain in the right arm and numbness in the right hand fin- } \\
\text { gers. At neurological examination,there was a slight loss of sensory modalities along the } \\
\text { right C6, C7, C8 dermatoms. Motor examination showed grade IV/V power in the right } \\
\text { elbow flexion.Biceps and triceps tendon reflexes were diminished. In the sagittal Magnetic } \\
\text { Resonance Images (MRI) there were a santrally localized mass lesion extending from C5 } \\
\text { to T1 vertebra level and expanding the cord. There were also a milimetric syringomyelia } \\
\text { cavity extending between T2-T4 vertebra . The tumour was removed totally . Pathological } \\
\text { diagnosis was compatible with grade II ependymoma (World Health Organization Central } \\
\text { Nervous System Tumour Classification 2007). No radiation therapy was advised to the } \\
\text { patient. These tumours are benign, slow-growing lesions which are optimally treated with } \\
\text { gross-total surgical resection without adjuvant therapy. Postoperative functional outcome } \\
\text { is related to preoperative functional status. Hence, early diagnosis prior to symptomatic } \\
\text { progression is critical to the successful treatment of these tumours. } \\
J . \text { Exp. Clin. Med., 2010; } 27: 114-117\end{array}$} \\
\hline Received $\quad 02 / 11 / 2010$ & \\
\hline Accepted $\quad 12 / 12 / 2010$ & \\
\hline * Correspondence to: & \\
\hline Ersoy Kocabıçak & \\
\hline Department of Neurosurgery & \\
\hline Ondokuz May1s University & \\
\hline Medical Faculty Samsun, Turkey & \\
\hline e-mail: ekocabicak@yahoo.com & \\
\hline Key Words : & \\
\hline Cervical Ependymoma & \\
\hline Intramedullary & \\
\hline Surgical Resection & \\
\hline
\end{tabular}

(C) 2010 OMU All rights reserved

\section{Introduction}

Ependymomas are uncommon Central Nervous System (CNS) neuroepithelial tumours arising from the ependymal cells lining the ventricular cavities of the brain and the central canal of the spinal cord, as well as from ependymal clusters in the filum terminale. (Barbagallo et al., 2009) Intramedullary ependymomas represent $34.5 \%$ of all central nervous system (CNS) ependymomas and approximately $60 \%$ of all intramedullary tumors (Schwartz and McCormick, 2000). Classical spinal ependymomas predominantly affect middle aged adults with an equal sex distribution (Alkhani et al., 2008). Although the cervical cord represents only $22.5 \%$ of spinal cord tissue, approximately $68 \%$ of tumours arise from or extend into the cervical cord (McCormick and Stein 1990). Approximately $65 \%$ will have associated syringes, particularly when presenting in cervical locations (Samii and Klekamp, 1994).

A variety of histologic sub-types may be encountered. Pathologically,they exhibit properties of a benign histology, World Health Organization grade II (Alkhani et al., 2008).

Depending on location, the spinal cord tumours present with varied symptomology, including neck or back pain and motor symptoms antedated by sensory symptoms (Cho et al., 2009). The nonspecific clinical presentation of a spinal cord tumour often results in delay of diagnosis with adverse outcomes. Although slow-growing, a prompt diagnosis of a spinal cord tumour is critical for the optimal postoperative functional outcome as prognosis is directly related to preoperative functional status (Schwartz and McCormick, 2000). It is generally accepted that the strongest predictive factor for postoperative functional outcome is the preoperative neurological status (Hoshimaru et al., 1999).

In the past, surgical resection was often with significant postop neurological morbidities. Recent advance in operative techniques and intraoperative neurophysiological monitoring have made the surgical resection a relatively safe procedure (Alkhani et al., 2008).

\section{Case Report}

A 51 year old man patient was presented with one month history of pain in the right arm and numbness in the right hand fingers. He complained of subacut onset of pain along the right side of the neck radiating to the upper lateral aspect of right arm. The pain was of a moderate 
to severe intensity accompained by numbness in the right hand fingers. He didn't have any kind of motor, sensory or autonomic symptoms. His general physical examination was normal. At neurological examination,there was a slight loss of sensory modalities along the right $\mathrm{C} 6, \mathrm{C} 7, \mathrm{C} 8$ dermatoms. Joint position and vibration sense were normal.No evidence of musculer atrophy was present. Power assesment showed grade IV/V power in the right elbow flexion. Biceps and triceps tendon reflexes were diminished and the other reflexes were normal.

\subsection{Neuroimaging findings}

In the sagittal MR images there were a santrally localized mass lesion extending from $\mathrm{C} 5$ to $\mathrm{T} 1$ vertebra level and expanding the cord.The lesion was hypointens in T1Weighted images and hyperintens in T2Weighted images. On contrast enhanced T1Weighted images, the lesion showed heterogenous enhancement. These imaging findings were suggestive of an intramedullary lesion. There were also a milimetric syringomyelia cavity extending between T2-T4 vertebra corpus which is seen hypointens in T1Weighted images and hyperintense in T2Weighted images (Fig.1).

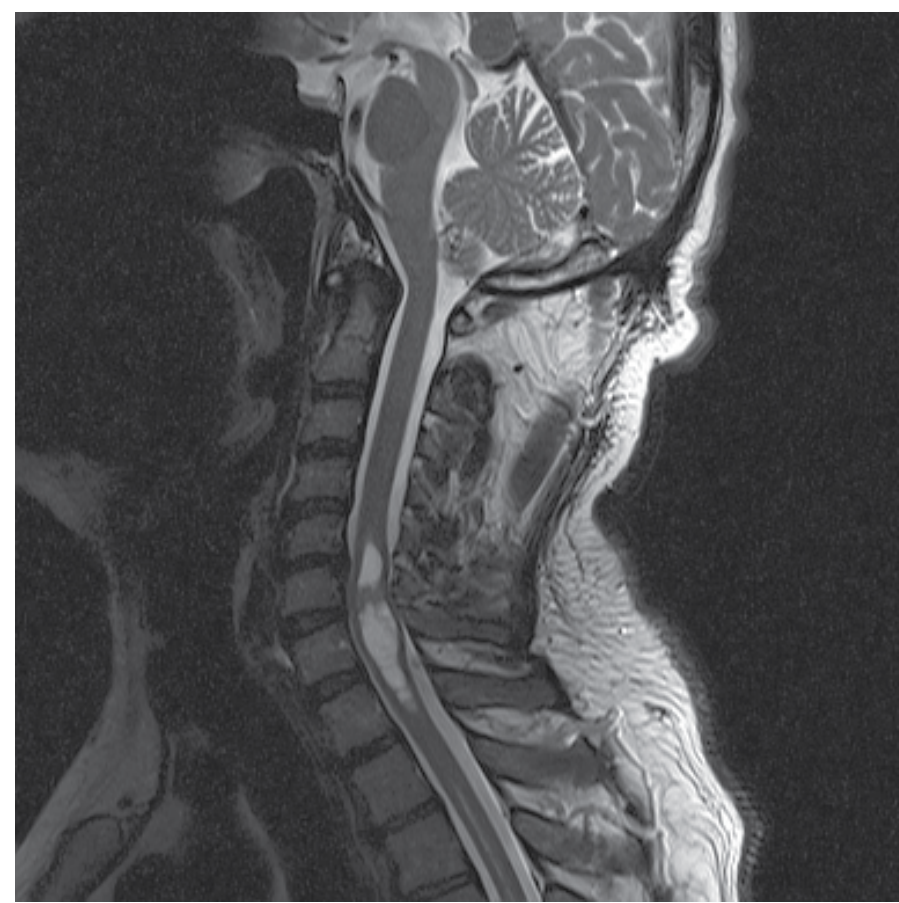

Fig.1. Preoperative sagittal T2W MRI showed the ependymoma as a hyperintense, centrally localized mass lesion extending between C5-T1 vertebra levels.

\subsection{Operative intervention}

A midline incision was performed between C4-T2 vertebra level with a Mayfield skull clamp.Total laminectomy of C5-C6-C7 was accomplished. The facets were preserved. The dura was opened in the midline under the operative microscope and a standart midline myelotomy was performed through the posterior median septum. Between C5-T1 levels a highly vascular, cleavable mass lesion was seen.The tumour was removed totally. Homeostasis was accomplished.The dura was sutured continually (Fig. 2)

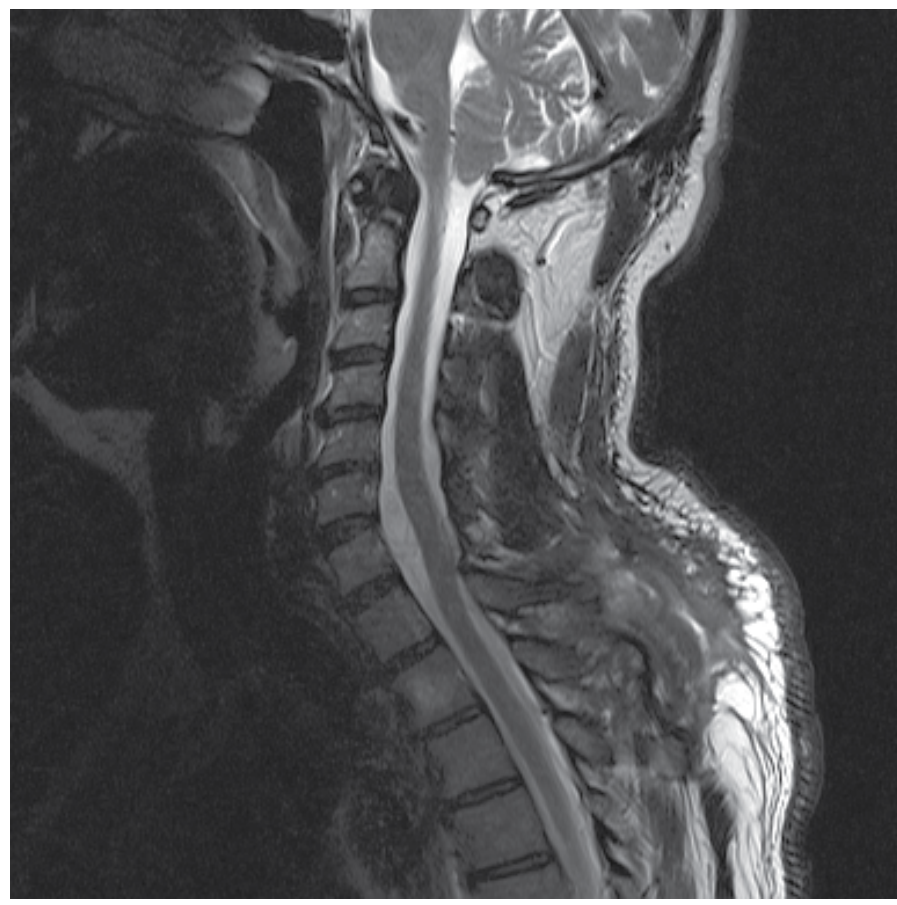

Fig.2. Postoperative sagittal T2W MRI showed the surgical resection and laminectomies noted at $\mathrm{C} 5, \mathrm{C} 6$ and $\mathrm{C} 7$.

\subsection{Histopathological examination}

Macroscopically, soft, brown coloured materials were obtained. Microscopically tumor was well circumscribed and it was arranged in sheets of spindle and epithelioid cells with round to oval nuclei containing small nucleoli. Some cells had clear cytoplasm. Perivascular pseudorosettes which consist of nucleer free zones around central blood vessels. Hypercellularity and frequent mitoses were not seen (Fig.3).

The pathological diagnosis was compatible with grade II ependymoma (WHO, 2007).

\subsection{Postoperative course}

Postoperatively there was no progression in the musculer power statue but numbness in the right hand fingers remained the same for 4 months following the operation then slightly disappeared. 3 weeks later craniospinal axis MR imaging was obtained. As There were no sign of seeding, radiation therapy was not advised to the patient.

\section{Discussion}

The clinical manifestations of intramedullary ependymoma are variable and nonspecific. The earliest symptom is usually dysesthesia (described as unpleasant hot or cold sensations).

In up to two thirds of the patients, back and neck pain is the main complaint (Kothbauer, 2007). It usually presents as diffuse, rather than following a radicular distribution. Other symptoms vary from painful aching sensations localized to the level of the tumor to mixed upper and lower neuron motor weakness and spastic lower extremities (Schwartz and McCormick, 2000). Another common complaint is numbness which typically progresses from distal to proximal (Schwartz and McCormick, 2000). Similarly, our patient presented with nonspecific 

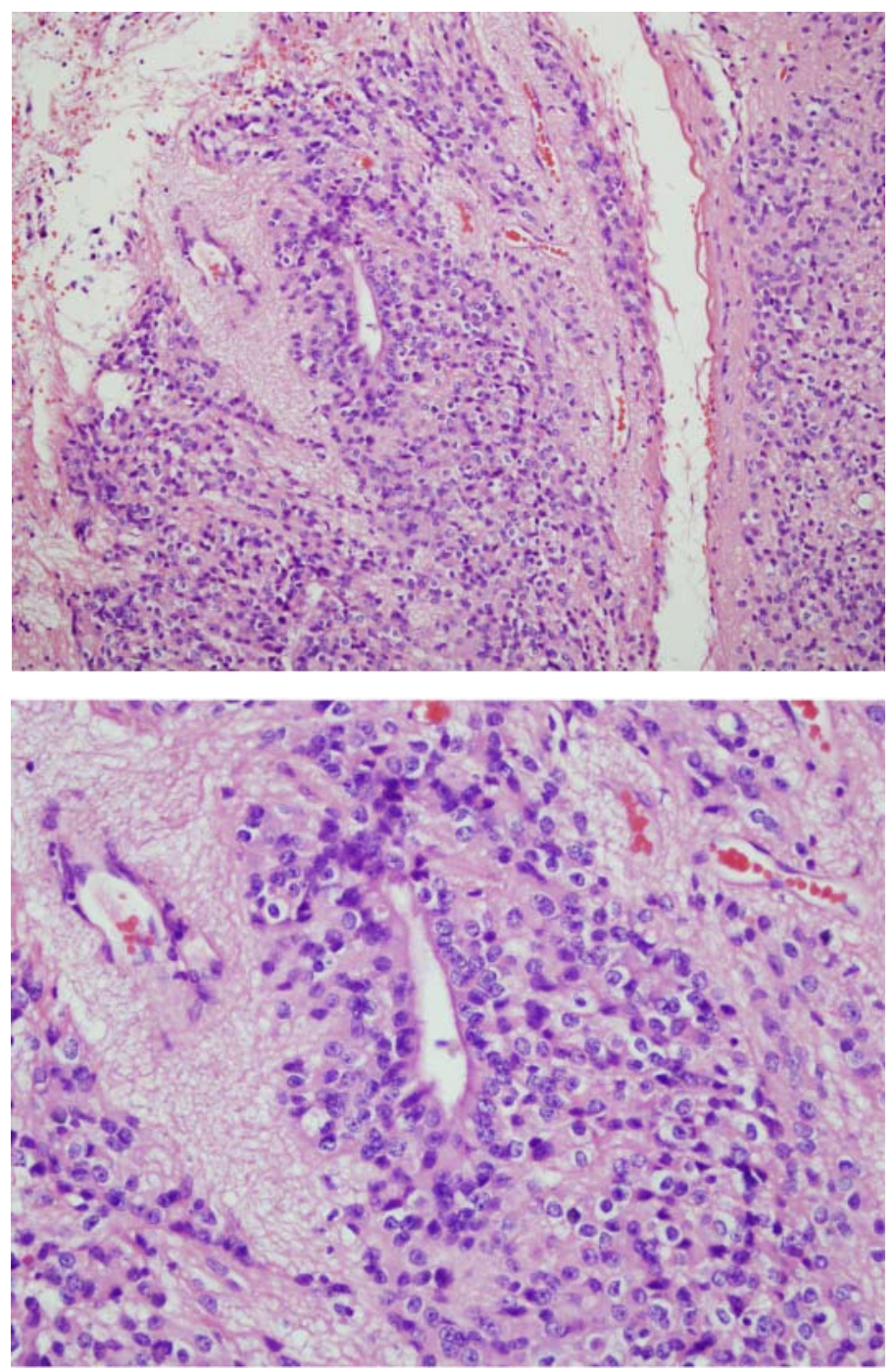

Fig. 3A-B. Pseudorossetes around the central blood vessels, Hematoxylin and eosin X 200 (A); X 400 (B)

symptomology as described in the literature including paresthesia and weakness but accompanied by signs of radiculopathy.

Because of patient's history of right arm pain, MRI was obtained. As it provides excellent contrast sensitivity and multiplanar capabilities without the use of ionizing radiation, MRI is the imaging modality of choice for evaluating tumours of the spine (Fine et al., 1995; Bloomer et al., 2006). MRI with intravenous contrast administration allows preoperative planning and discrete tumour plane localization. MRI also provides detailed information regarding the tumour involvement relative to the spinal neural anatomy (ie, nerve roots, thecal sac and spinal cord) (Bloomer et al., 2006). Spinal cord ependymoma may present on MRI as iso-or hypointense signal on $\mathrm{T} 1 \mathrm{~W}$ images that become hyperintense on $\mathrm{T} 2 \mathrm{~W}$ images. However, with a mucinous component or hemorrhage in the tumour, the signal may become hyperintense on T1W images. The retrospective review by Fine et al stated that $35 \%$ of the spinal cord ependymomas showed uniform contrast enhancement, whereas $65 \%$ had heterogeneous enhancement with intravenous gadopentetate dimeglumine administration. Another manifestation included low signal intensity rims in the margins of the tumour on $\mathrm{T} 2 \mathrm{~W}$ images (Fine et al., 1995).

The majority of benign intramedullary spinal ependymomas are amenable to gross total resection correlated clearly with good functional results and a low incidence of recurrence because of their benign and minimally infiltrative nature, having a distinct cleavage plane between the tumour and normal cord tissue (Kyoshima et al., 2009). Surgery is the best treatment for ependymoma as it delivers a histological diagnosis and prevents long-term neurological dysfunction (Kothbauer, 2007). According to Nakamura and colleaguescomplete resection was accomplished in $30(91 \%)$ of the 33 cases (Nakamura et al., 2008). Although recurrence is unusual, radiotherapy is indicated in those with subtotal resections or with recurrent tumours. Late recurrence has been known to occur up to 12 years after surgery; thus, long-term clinical and imaging surveillance is warranted (Bloomer et al., 2006).

According to the World Health Organization (WHO) classification, the term ependymoma comprises a histologically heterogeneous group of tumours that include cellular, papillary, clear cell and tanycytic subtypes. Ependymoma with lipomatous differentiation, ependymoma with extensive tumour cell vacuolization, melanotic ependymoma, signet-ring cell ependymoma and GCE are rare variants (Barbagallo et al., 2009). Histological diagnosis is crucial to consideration of postoperative adjuvant therapy for intramedullary tumours of the spinal cord. In most patients with ependymoma of the spinal cord, the tumour can be totally removed, and postoperative adjuvant therapy is not required after complete resection (Akutsu et al., 2000). On the basis of the histological diagnosis in our patient, gross total removal was accomplished and postoperative radiation therapy was not administered.

\section{Conclusion}

Cervical intramedullary ependymoma is a rare, slow growing spinal cord tumour. Surgical resection is the choice of treatment with infrequent recurrence. Early detection of the tumour is essential for optimal postoperative functional status.

\section{REFERENCES}

Akutsu, H., Shibata, Y., Okazaki, M., Hyodo, A., Matsumura, A., 2000. Intramedullary clear cell ependymoma in the cervical spinal cord: case report. Neurosurgery. 47, 1434-1437.

Alkhani, A., Blooshi, M., Hassounah, M., 2008. Outcome of surgery for intramedullary spinal ependymoma. Ann Saudi Med. 28, 109-113.

Barbagallo, G.M., Caltabiano, R., Parisi, G., Albanese, V., Lanzafame, S.,2009. Giant cell ependymoma of the cervical spinal cord: case report and review of the literature. Eur. Spine J. 18, 186-190. 
Bloomer, C.W., Ackerman, A., Bhatia, R.G., 2006. Imaging for spine tumors and new applications. Top Magn. Reson. Imaging. 17, 69-87.

Cho, J.C,, Miller, A., Kettner, N.W., 2009. Cervical ependymoma in a male adolescent with neck and back pain. J. Manipulative Physiol. Ther. 32, 695-700.

Fine, M.J., Kricheff, I.I., Freed, D., Epstein, F.J., 1995. Spinal cord ependymomas: MR imaging features. Radiology 197, 655-658.

Hoshimaru, M., Koyama, T., Hashimoto, N., Kikuchi, H., 1999. Results of microsurgical treatment for intramedullary spinal cord ependymomas: analysis of 36 cases. Neurosurgery 44, 264-269.

Kothbauer, K.F., 2007. Neurosurgical management of intramedullary spinal cord tumors in children. Pediatr. Neurosurg. 43, 222-235.

Kyoshima, K., Akaishi, K., Tokushige, K., Muraoka, H., Oikawa, S., Watanabe, A., Koyama, J., Kobayashi, S., Unoki, T., Goto, T., Wada, N., Uehara, T., 2004. Surgical experience with resection en bloc of intramedullary astrocytomas and ependymomas in the cervical and cervicothoracic region. J. Clin. Neurosci. 11, 623-628

McCormick, P.C, Stein, B.M., 1990. Intramedullary tumors in adults. Neurosurg. Clin. N. Am. 1, 609-630.

Nakamura, M., Ishii, K., Watanabe, K., Tsuji, T., Takaishi, H., Matsumoto, M., 2008. Surgical treatment of intramedullary spinal cord tumors: prognosis and complications. Spinal Cord 46, 282-286.

Samii, M., Klekamp, J., 1994. Surgical Results of 100 Intramedullary Tumors in Relation to Accompanying Syringomyelia Neurosurgery 35, 865-873.

Schwartz, T.H., McCormick, P.C., 2000. Intramedullary ependymomas: clinical presentation, surgical treatment strategies and prognosis. J. Neurooncol. 47, 211-2118. 